\title{
A escolha do cuidado alternativo para o bebê e a criança pequena ${ }^{1}$
}

\author{
Andrea Rapoport \\ Cesar A. Piccinini \\ Universidade Federal do Rio Grande do Sul
}

\begin{abstract}
Resumo
A escolha de um cuidado alternativo para o bebê ou criança pequena geralmente não é tarefa fácil para os pais e envolve a análise de vários fatores. Isto fica mais difícil ainda quando esta escolha precisa ser feita nos primeiros meses de vida do bebê. O presente artigo tem por objetivo discutir os fatores que influenciam na escolha de um cuidado alternativo (i.e., parente, babá, creche) para o bebê e criança pequena e as vantagens e desvantagens apontadas pelos pais para as diferentes formas de cuidado. Dentre os fatores envolvidos no processo de decisão dos pais estão: a situação financeira e social da família; o apoio social recebido nos cuidados da criança; as práticas e crenças parentais sobre o cuidado das crianças; a escolaridade dos pais; a idade da criança; e o grupo étnico. Os estudos apontam que um cuidado alternativo adequado não só tranqüiliza os pais, como contribui para o desenvolvimento do bebê e para que seja mantida a qualidade da interação pais-bebê.
\end{abstract}

Palavras-chave: cuidados alternativos; creche; apoio social; bebê

\begin{abstract}
The choice of an alternative care for the infant. The choice of an alternative care for the infant is not an easy task for parents and it involves the analysis of several factors. It is even harder when this choice has to be made in the first months of the baby's life. This article aims to discuss the factors which have influence in choosing an alternative care (i.e., relatives, baby sitter, and day care) for the infant, and the advantages and disadvantages mentioned by parents for the different ways of care. The factors involved in the decision process for the parents are: the financial and social status of the family, the social support received in taking care of the child, and the ethnic group. Research shows that a proper alternative care not only relaxes and reassures parents as well as contributes to the development of the infant and keeps the quality of the parentchild bond.
\end{abstract}

Keywords: daycare; daycare center; social support; infant

$\mathrm{O}$ nascimento de um filho é um evento que traz mudanças para a vida do casal, especialmente para a mãe. A resposta da mulher a estas mudanças é influenciada por fatores individuais, familiares, ambientais e sócio-econômicos. Um dos fatores mais importantes que influencia o bem estar da mulher neste período é o apoio que ela recebe daqueles que a rodeiam, principalmente do pai do bebê (DunkelShetter, Sagrestano, Feldman, \& Killingsworth, 1996). Este apoio dado pelo pai do bebê geralmente é complementado por outras formas de apoio social dado por familiares, amigos, empregados ou instituições formais (i.e. creche e préescola).

O emprego materno tem exigido novas opções para o cuidado regular de bebês e crianças pequenas. É freqüente o retorno da mulher ao trabalho logo após os primeiros meses de vida do bebê, sendo necessário que alguém cuide dele enquanto os pais trabalham. A migração de pessoas do inte- rior para as grandes cidades tem levado a uma diminuição no número de familiares convivendo em proximidade geográfica, quebrando a rede de apoio familiar e de vizinhança e gerando um distanciamento físico e psicológico entre os diferentes membros da família extensiva. Soma-se a isto o fato de as próprias famílias terem diminuído de tamanho nas últimas décadas, além de mudanças no comportamento dos seus membros, com uma tendência a viverem mais isolados e a buscarem maior individualidade. Tudo isto parece ser facilitado pelo isolamento característico da vida em apartamentos das cidades modernas e pela própria vida agitada dos grandes centros urbanos. Neste contexto, as relações com a família extensiva, e mesmo com a vizinhança e amigos, acaba sendo afetada. Desse modo, a creche ou a empregada/babá tem se revelado, muitas vezes, a opção disponível para os cuidados do bebê. Mesmo as mulheres que não trabalham fora têm procurado um espaço de socialização para as crianças, já que 
hoje contam com poucos recursos no espaço doméstico. A socialização das crianças também é apontada como uma vantagem da creche em comparação ao cuidado familiar, tendo em vista, muitas vezes, a ausência de outras crianças da mesma idade para brincar e porque, muitas vezes, os espaços são inseguros e pequenos (Loviloso, citado por Rosemberg, 1995).

Os cuidados alternativos se referem às formas de cuidados não-parentais, das quais se destacam quatro tipos principais (Davies \& Thornburg, 1994): 1) creches e pré-escolas; 2) creche familiar (pequeno grupo de crianças na casa do cuidador); 3) cuidado na casa da criança por uma babá/empregada; e, 4) parente, na casa da criança ou na sua casa. A entrada de bebês em cuidados alternativos, especialmente durante o primeiro ano de vida, tem gerado controvérsias no meio científico e leigo, pois implica em separações diárias do bebê de sua mãe enquanto ele ainda é muito pequeno. Além disso, a interação mãe-criança, inicialmente restrita ao espaço domiciliar, onde há uma maior intimidade e exclusividade, acaba afetada quando ocorre separação freqüente da díade, o estabelecimento de novas relações e o fim da exclusividade nos cuidados (Rossetti-Ferreira, Amorim, \& Vitória, 1994). É comum os pais se sentirem inseguros e desconfiados, principalmente quando se trata do primeiro filho, que ainda é bebê. Sendo assim, as mães experienciam sentimentos ambivalentes, conscientes ou inconscientes, sobre deixar suas crianças aos cuidados de outras pessoas (McMahon, 1994). Estes sentimentos podem ser devido à visão prevalente na sociedade de que a mãe tem de cuidar de forma exclusiva dos pequenos, porque os pais preocupam-se com a competência do cuidador substituto, ou até têm ciúmes deste (Rossetti-Ferreira et al., 1994). Estas autoras assinalaram, ainda, que os sentimentos dos pais também podem ser permeados por suas representações sociais sobre a creche, pelos pré-conceitos que trazem de sua experiência de vida e que irão influenciar sua relação com a instituição, a forma como irão introduzi-la à criança e o significado que lhe será dado.

O perfil das famílias que procuram a creche tem se alterado nas últimas décadas (Rosemberg, 1995). Inicialmente, elas eram utilizadas principalmente por famílias operárias e de classe média cuja mãe precisava trabalhar; só mais tarde passaram a ser procuradas por famílias mais ricas que acabaram impondo-lhes novos padrões de qualidade. Segundo Rosemberg, o aumento da oferta desses serviços e a melhoria de sua qualidade, por sua vez, favoreceram a entrada de mais mulheres no mercado de trabalho, já que dispunham de mais uma opção para cuidado da criança.

Contudo, apesar das transformações sofridas pela creche, ela continua sendo encarada por muitas famílias como uma instituição ainda pouco confiável para a realização dos cuidados da criança pequena (Amorim, 1997). Para Amorim, a sua estrutura básica de funcionamento pode, muitas vezes, entrar em conflito com valores socialmente incentivados, como a busca de identidade e individualidade. Na creche, o espaço físico e os brinquedos são comuns, as atividades são compartilhadas pelas crianças e momentos considerados íntimos, como o banho e a amamentação, tornam-se públicos. Um outro fato é que, tradicionalmente, a educação cabe ao adulto, em virtude de sua maior experiência. Na creche, a proporção adulto-criança é pequena e o parceiro mais disponível para interação são outras crianças .Isso pode levar os pais a crer que faltam cuidados apropriados a cada criança. Alguns pais consideram, ainda, a maior interação com parceiros pequenos "perigosa", tanto em termos de influências sobre o comportamento da criança, como em relação à integridade física dos filhos. Por fim, o desempenho profissional das educadoras é, muitas vezes, questionável, devido à longa jornada de trabalho associada a uma má remuneração. Dentro desse contexto, para Amorim, existiria ainda uma indefinição sobre qual a principal função da creche: apenas atender as crianças enquanto as mães trabalham, ou ser um contexto educativo para o desenvolvimento da criança. Pode-se pensar que com uma melhor qualificação das creches esta dicotomia seja reduzida, e elas deixem de ser vistas como apenas dispensando cuidados básicos à criança e passem a ser vistas na sua função mais educativa.

Vários estudos estadunidenses e europeus têm investigado as conseqüências dos cuidados alternativos sobre o desenvolvimento infantil, em especial sobre o apego mãebebê, mas eles têm relatado resultados muitas vezes inconsistentes. Além disso, a revisão da literatura também mostra que existem poucos estudos que exploram as atitudes dos pais em relação aos cuidados infantis, suas escolhas de cuidados alternativos dentro e fora de casa e suas expectativas em relação aos mesmos (Long, Wilson, Kutnick, \& Telford, 1996). Sabe-se muito pouco sobre quais fatores influenciam a escolha do tipo de cuidado alternativo pelos pais, e por isto, corre-se o risco de atribuir efeitos à creche apenas pelo seu contexto, quando, na verdade, as eventuais conseqüências sobre o desenvolvimento da criança ocorrem através da interação entre os contextos de cuidados familiar e alternativo em que os pais colocaram a criança (Fuller, Holloway, \& Liang, 1996; Singer, Fuller, Keiley, \& Wolf, 1998). As pesquisas sobre escolha do cuidado alternativo, muitas vezes, enfatizam o emprego materno e as condições para pagar pelo cuidado alternativo e poucas têm focado os fatores sociais que podem explicar a escolha do cuidado alternativo, tais como a idade da criança, o tamanho da família, a disponibilidade do marido ou a proximidade de parentes (Fuller et al., 1996).

$\mathrm{Na}$ falta de uma política governamental e de um consenso da sociedade sobre os cuidados alternativos, os pais têm que tomar uma decisão individual e complexa sobre o cuidado do bebê e da criança pequena. Em geral, confiam na família extensa e na comunidade para se informar e legitimar suas decisões (Hertz \& Ferguson, 1996), mas, muitas vezes, não ficam satisfeitos com as mesmas (Long et al., 1996). Essa insatisfação pode estar associada a questões individuais, familiares, falta de informações adequadas para decidir, falta de preparo dos pais para fazerem essa escolha e também à falta de opções dentro de suas condições socioeconômicas. Existem casos, ainda, em que os pais dependem da disponibilidade de vagas na creche mantida no local de trabalho ou na rede pública e devem aceitar a instituição que lhes é designada. 
O que motiva os pais a colocarem a criança em cuidados alternativos e a escolha do tipo de cuidado também podem influenciar na reação e na adaptação de bebês e crianças pequenas a esses cuidados (McKim, Stuart, \& O'Connor, 1996). A partir destas questões iniciais, pretende-se discutir quais os fatores que estão associados à escolha de um cuidado alternativo para o bebê e para a criança pequena, bem como à satisfação dos pais com o mesmo.

\section{Fatores associados à escolha dos cuidados alternativos}

Existem inúmeras diferenças culturais e sociais associadas às escolhas de cuidados alternativos feitas pelos pais. Por exemplo, no contexto brasileiro, uma pesquisa realizada pela revista Veja ("Sua criança", 1998) apontou que quando a mulher trabalhava fora grande parte dos bebês e crianças pequenas ficavam aos cuidados de outros parentes (44\%), da empregada/babá (15\%), da creche (14\%), da filha mais velha (13\%), do marido (5\%), de amigos e vizinhos (4\%) e do filho mais velho (2\%). Já nos Estados Unidos, Scarr (1998) verificou que grande parte das crianças ficava com o pai (40\%), com outros familiares $(21 \%)$, na creche $(31 \%)$, nas creches familiares (14\%) e com babás/empregadas (4\%). Algumas crianças estavam em mais de um arranjo de cuidado alternativo (9\%). Segundo Scarr, o uso da creche aumentou nos últimos trinta anos, passando de $6 \%$ das crianças atendidas em 1965, para $31 \%$ em 1995. Embora as duas pesquisas tenham usado metodologias diferentes e não sejam equiparáveis, os resultados indicam que o apoio recebido por familiares é semelhante no Brasil (64\%) e nos EUA (61\%). Contudo, o pai parece ter um papel mais expressivo no apoio à mãe nos EUA (40\%) do que no Brasil (5\%). Já no Brasil, menos crianças (14\%) freqüentam a creche do que nos EUA (44\%), incluindose nesta análise a creche familiar. Por outro lado, o cuidado realizado pelos amigos e vizinhos só foi mencionado na pesquisa brasileira.

Com relação à educação infantil no Brasil, a Lei de Diretrizes e Bases da Educação Nacional (1996) define que essa educação infantil deve ser oferecida em creches ou em entidades equivalentes, para crianças de 0 a 3 anos de idade, e em pré-escolas, para crianças de 4 a 6 anos. Um levantamento realizado recentemente mostrou que a educação infantil brasileira está em expansão (INEP/MEC, 2001). Os dados revelaram que a maioria dos municípios brasileiros oferece algum tipo de educação infantil. Existem 92.526 estabelecimentos de educação infantil no país que atendem crianças entre 0 e 6 anos de idade, sendo que $67 \%$ pertencem às redes de educação municipais. Em relação ao número de matrículas em educação infantil, o número de crianças matriculadas atingiu, no ano de 2000, o índice de 1.093.347, sendo 886 em instituições federais, 18.292 em estaduais, 663.508 em municipais e 410.661 em instituições particulares. Apesar de a educação infantil ser definida como de responsabilidade dos municípios, estes dados mostram que grande parte das famílias precisam recorrer a instituições particulares para que seus filhos pequenos sejam atendidos. O custo financeiro desta opção é, por vezes, tão alto que não compensa que a mãe saia de casa para trabalhar. É comum que o salário que ela recebe não lhe permita pagar a creche do filho, o que a leva a optar por cuidados alternativos menos qualificados.

A escolha de um cuidado alternativo para o bebê ou criança pequena, geralmente, não é tarefa fácil para os pais e envolve considerações sobre vários fatores (Fuller et al., 1996), dentre os quais se destacam os seguintes: 1) Economia familiar: depende da participação da mulher no mercado de trabalho, do preço do cuidado alternativo e subsídios governamentais ou de empresas; 2) Estrutura social da família e apoio social para cuidado da criança: o pai é o principal recurso para cuidado da criança em algumas famílias, seguido por outro adulto que mora na casa e pela presença de irmãos; 3) Práticas e crenças parentais sobre o cuidado das crianças: são as concepções dos pais sobre como educar a criança e suas expectativas em relação a ela, incluindo a importância de colocá-la em atividades educacionais desde pequena; 4) Grupo étnico: pode significar diferenças na estrutura social e econômica relacionadas às oportunidades para obter cuidado para a criança; 5) Escolaridade dos pais: geralmente está associada a fatores como posição social, atitudes em relação à escolarização e desenvolvimento infantil, bem como aos recursos disponíveis; e, 6) Idade da criança: pode ser um determinante na escolha da creche, pois as crianças são mais prováveis de participar de creches/pré-escolas à medida que se aproximam dos cinco anos.

Em um estudo realizado por Buffardi e Erdwins (1994) participaram 263 mães que utilizavam três tipos de cuidados alternativos para seus filhos pré-escolares: creches familiares, creches e babás. Questionadas sobre sua satisfação com estes tipos de cuidados, as mães com melhor escolaridade e renda mais elevada haviam mais frequientemente optado por alguém que cuidasse da criança em sua própria casa. A idade da criança também foi um fator importante e, como era de se esperar, crianças mais velhas foram mais frequientemente colocadas em creche.

No extenso estudo de Fuller et al. (1996), eles contataram 4761 famílias com pelo menos uma criança entre 3 e 5 anos que não tivesse iniciado a pré-escola, para investigar o contexto de cuidado da criança, características sociais e educacionais, informações demográficas e econômicas e práticas parentais. Os resultados mostraram que os pais colocavam mais a criança na creche, em detrimento de outras formas de cuidado, quando a escolaridade da mãe era mais alta, a criança era mais velha e/ou a mãe tinha menor apoio social disponível, como, por exemplo, um avô residindo com a família. De uma forma geral, as famílias ricas utilizaram mais a creche e as famílias com renda mais baixa só a procuraram quando recebiam alguma forma de subsídio governamental ou da empresa em que trabalhavam. Práticas parentais relacionadas à alfabetização precoce e supervisão próxima da criança (e.g., limitar o tempo de a criança assistir TV) estiveram, da mesma forma, relacionadas à escolha da creche.

Hertz e Ferguson (1996) também investigaram como os pais tomavam a decisão sobre os cuidados da criança. Os autores verificaram que, entre diversos fatores, as decisões sobre os cuidados da criança estavam relacionadas a senti- 
mentos implícitos na família e às opções dentre as quais os pais podiam escolher. Os principais tipos de cuidado alternativo mencionados pelos pais deste estudo foram: empregada que morava ou não na casa com a família e creche. Muitas famílias complementavam a forma de cuidado selecionada com outros adultos que proviam um cuidado em momentos especiais (e.g., quando a criança estava doente ou no horário de transição entre um arranjo de cuidado alternativo e a chegada dos pais). Segundo os autores, a concepção sobre maternidade da própria mãe e a sua orientação para a família ou para o trabalho, o seu grupo étnico e o seu nível sócio-econômico estavam relacionadas à escolha do cuidado alternativo. Por exemplo, para as mães acostumadas a trabalhar para ajudar no sustento da família, deixar o filho aos cuidados de terceiros não representava uma crise. Para esses casais, uma opção para o cuidado não-familiar eram as instituições formais (i.e., creches, pré-escolas), especialmente quando eles não tinham espaço em suas casas para algum empregado morar, ou quando já haviam tido uma experiência negativa com isto. Os autores também salientaram que, muitas vezes, a mulher pode se sentir ambivalente quanto à outra mulher cuidar de seu filho em sua própria casa. Quando a mãe leva o filho para creche, está levando para uma instituição, e não para outra pessoa. Existe uma diferença entre uma estranha em casa e uma estranha na instituição. A estranha em casa estaria cuidando do filho no lugar dela enquanto que a estranha na creche estaria educando, ensinando, e não ocupando o lugar de mãe. Já para os casais orientados para a família, cuidar da criança estava acima de tudo, de forma que eles só pensavam em cuidar pessoalmente da criança ou delegar a um familiar que tivesse os mesmos valores que eles.

Num estudo semelhante, Singer et al. (1998) buscaram identificar o cuidado alternativo escolhido por cada família, e em que idade ocorria o ingresso nestes cuidados. Foram entrevistadas 2.614 famílias americanas com um filho de até seis anos, das quais 1881 já tinham colocado a criança em cuidados nãoparentais antes da entrevista e 733 ainda não. A média de idade com que as crianças ingressaram em cuidados alternativos foi de 33 meses. Quase um quarto das crianças foi colocado em cuidados alternativos pela primeira vez nos seus primeiros cinco meses de vida. Entre as crianças não colocadas nos primeiros cinco meses, $10 \%$ entraram entre seis e onze meses, $7 \%$ entre doze e dezessete, e $6 \%$ entre dezoito e vinte e três meses. Aos dois anos cerca de $40 \%$ das crianças estavam em cuidados não-parentais e, aos cinco anos, $59 \%$.

De acordo com os autores, existiriam três explicações sobre o porquê de as famílias diferirem em sua propensão para selecionar um cuidado alternativo: situação econômica, estrutura demográfica da família e as opções disponíveis de cuidados alternativos. Dentre as crianças que freqüentavam cuidados alternativos, mais da metade (1045) permanecia nesses cuidados por mais de 20 horas semanais e os demais até 10 horas. Os resultados apontaram na mesma direção do estudo de Fuller et al. (1996), indicando que quanto maior a escolaridade da mãe, maior a probabilidade dela colocar a criança em cuidados alternativos. Entretanto, no estudo de Singer et al (1998), o status conjugal, o emprego materno e o tamanho da família influenciaram mais na idade média de ingresso na creche do que a escolaridade materna. Já o principal preditor do ingresso em cuidados alternativos durante o primeiro ano de vida, geralmente antes dos seis meses, foi o fato da mãe trabalhar desde a gestação. Apesar de o emprego materno ser um importante preditor da escolha de um cuidado alternativo, um terço das crianças filhas de mães que não trabalhavam também foram colocadas em cuidados não-parentais, e isto não tinha relação com a renda familiar. Outro preditor de escolha de um cuidado alternativo foi o número de filhos. Mulheres com até dois filhos, ou solteiras com um único filho, tenderam a escolher a creche. Por outro lado, quanto mais filhos os pais tinham, menor foi a probabilidade de escolherem um cuidado nãoparental, ou eles escolhiam formas mais baratas. O custo dos cuidados alternativos acabava levando as mulheres com muitos filhos a permanecerem em casa. A disponibilidade de adultos que davam apoio na família também apareceu associada com a seleção do cuidado não-parental. Mulheres casadas, que demoraram a engravidar e com mais idade quando tiveram o filho, também tenderam menos a colocar o filho em cuidados alternativos regulares. As famílias de classe baixa utilizaram mais familiares e menos instituições formais, comparadas com as famílias de classe média.

Como foi assinalado pelos estudos revisados acima, um dos fatores que pesa muito na escolha de cuidado alternativo para um bebê e criança pequena é a sua idade. Existem fases durante as quais tende a ser mais difícil para a criança lidar com separações e, por isto, seriam mais negativas para o desenvolvimento infantil. Varin, Crugnola, Molina, e Ripamonti (1996) estudaram crianças que estavam no terceiro ano de vida e que haviam ingressado no mesmo tipo de creche entre os 6 e 36 meses de idade. Os resultados mostraram que nem todas as crianças que ingressam na creche antes de um ano apresentariam risco de desenvolver problemas psicológicos, mas que algumas seriam menos capazes em lidar com o estresse da separação precoce. Em particular, mais crianças que entraram na creche entre 6-11 meses e 18-23 meses experienciaram reuniões difíceis com os pais, em comparação com aquelas que entraram entre 12-17 meses, ou depois dos 24 meses. O grupo de 6-11 meses apresentou também mais dificuldade de tolerar frustração. Além disso, os resultados também endossaram a hipótese de que as separações da mãe devido à entrada na creche durante a segunda metade do primeiro ano poderiam introduzir algum distúrbio na construção do apego mãe-bebê. Por outro lado, crianças que ingressaram na creche mais cedo mostraram níveis mais elevados de brinquedo e comunicação com as educadoras. Isto pode ser devido ao fato de que crianças que entram mais cedo numa creche de boa qualidade têm mais oportunidades e tempo para aprender a brincar com outras crianças. Os resultados indicaram que o grupo que ingressou entre 12-17 meses, ou depois de 24 meses, apresentou menos problemas em lidar com a experiência diária da creche, podendo constituir-se num período melhor para ingressar na creche.

Alguns estudos têm investigado, em particular, a influência do temperamento sobre a decisão de colocar a criança em cuidados alternativos no primeiro ano de vida da criança. Con- 
tudo, as evidências parecem ainda inconsistentes. Enquanto alguns autores enfatizaram que um bebê com temperamento difícil pode levar uma mãe a retornar mais cedo ao emprego (Zigler \& Hall, 1994, citados por Carey \& McDevitt, 1997), outros autores constataram que um bebê com temperamento difícil pode levar a mãe a permanecer em casa (Galambos \& Lerner, 1987), pois essa mãe poderia acreditar que ela seria a pessoa que teria mais paciência e disponibilidade para atendê-lo.

Ainda com relação ao temperamento infantil, alguns autores apontaram que determinados traços do temperamento da criança podem ajudar ou dificultar na sua entrada na creche dependendo das características da instituição escolhida (Carey \& McDevitt, 1997). Por exemplo, uma criança com horários altamente regulares, que está acostumada a comer e a evacuar sempre nos mesmos horários e entra numa creche sem uma continuidade nos horários, pode ter dificuldade em se adaptar. Por outro lado, se estiver numa instituição mais organizada, isto não vai ser problema. Para o caso de crianças muito sensíveis ao barulho, que tendem a acordar com facilidade, uma creche sem uma área de descanso com silêncio não seria adequada. Obviamente, existem crianças que são capazes de adormecer no meio de uma sala com outras pessoas conversando. Estas particularidades das crianças que podem afetar sua adaptação precisam ser consideradas quando os pais escolhem o local para colocá-la.

\section{Vantagens e desvantagens das diferentes formas de cuidados alternativos}

A satisfação das mães com os diferentes tipos de cuidados alternativos foi examinada por Buffardi e Erdwins (1994). A opção por alguém que cuidasse da criança em sua própria casa, geralmente a opção mais cara, facilita a vida da família, que não tem de conduzir a criança para outro local, além de proporcionar uma atenção mais individualizada para a criança. As mães das crianças que estavam em creches apontaram os benefícios educativos e de socialização da criança, embora tenham se mostrado menos contentes em relação à flexibilidade para levar e buscar a criança, bem como para cuidá-la quando ela estava doente. Tal situação exigia que disponibilizassem alguém para cuidar dela nessas ocasiões. Além disso, as mães estiveram significativamente menos satisfeitas com a quantidade de atenção que a criança recebia na creche. $\mathrm{O}$ que pareceu caracterizar mais a satisfação dos pais neste tipo de cuidado alternativo foi a comunicação com o cuidador e o custo/conveniência. Lordelo (1997) também relatou que na creche existe uma deficiência maior em termos de responsividade dos adultos pois, geralmente, são muitas crianças para poucos adultos, dificultando um atendimento individualizado.

Em um estudo posterior Erdwins, Casper, e Buffardi (1998) também examinaram a satisfação de mães e pais com os cuidados alternativos, num estudo envolvendo 250 crianças que eram cuidadas por um parente, 512 que estavam em creche familiar, 772 que estavam em creches e 141 que eram cuidadas por babás. Os resultados revelaram níveis mais elevados de satisfação com os cuidados providos por parentes e babás, realizados na própria residência dos pais, em comparação às creches e creches familiares. Segundo os autores, o cuidado por um parente assegura aos pais que a criança está num ambiente afetivo, além de ser mais barato. Por outro lado, apesar de mais caro do que uma creche, o atendimento por uma babá oferece economia de tempo, quando se considera a necessidade de levar e buscar a criança e as situações em que a criança fica doente, além de a babá contribuir com algumas tarefas domésticas. A satisfação dos pais com estas duas últimas formas de cuidados (i.e., parente ou babá) não diferiu significativamente. As mães, em geral, se mostraram mais satisfeitas do que os pais com o cuidado alternativo escolhido. Uma explicação dos autores é de que os pais tendem a se mostrar mais satisfeitos com as formas de cuidados que minimizam os custos e os seus esforços. Além disto, eles parecem ambivalentes quanto ao fato da esposa trabalhar e deixar o filho em cuidado alternativo. Já a mãe vê o cuidado alternativo como um recurso que lhe possibilita trabalhar e isto contribui para sua avaliação mais positiva do que a dos pais.

Alguns pais parecem particularmente satisfeitos com a creche em função da estimulação emocional e intelectual oferecida nestes locais (Roopnarine, citado por Buffardi \& Erdwins, 1994). Já os pais que utilizavam cuidados alternativos na própria casa pareciam se preocupar mais com o bem estar emocional e menos com a influência dos pares. Além disto, para Scarr (1998) os pais têm mais controle sobre a segurança da criança quando está na creche do que quando está em outras formas de cuidado. Isso inclui a própria casa, onde elas nem sempre são supervisionadas, ficando, por exemplo, expostas a muitas horas frente à televisão. Além disso, em casa, outros familiares, ou mesmo a babá, podem não seguir as preferências de cuidado dos pais.

\section{Considerações finais}

A literatura revisada e o senso comum mostram que a escolha de um cuidado alternativo para um bebê ou criança pequena não é tarefa fácil. Os pais, geralmente, são tomados por dúvidas acerca da melhor forma de cuidado para o filho e, quando precisam fazer esta escolha, se questionam sobre a melhor idade para colocar a criança numa forma de cuidado não-parental. Esta escolha é feita, muitas vezes, a partir de conversas informais com parentes e amigos. Não se encontra na literatura consenso sobre as vantagens e desvantagens de cada forma de cuidado alternativo, nem quanto às suas conseqüências para o desenvolvimento infantil. Os achados são, muitas vezes, inconsistentes, seja quanto às formas mais adequadas de cuidado alternativo, seja com relação à satisfação dos pais pelas escolhas realizadas. Na verdade, há uma diversidade de fatores que afetam tanto a escolha do cuidado alternativo como a adaptação da criança e a satisfação dos pais. Entre estes, destacam-se desde questões culturais sobre a melhor forma de cuidado alternativo, passando pelas condições sócio-econômicas e pelas características da própria criança, dos pais e da família, e envolve, obviamente, a qualidade do atendimento dispensado pela creche. Todos estes fatores interagem sinergicamente e um deles pode potencializar a ação de outro, para uma determinada criança e não para outra. 
Embora os fatores apareçam muito relacionados uns aos outros, alguns, em particular, parecem ter um efeito mais direto e destacado para a escolha de cuidado alternativo. É o caso, por exemplo, da escolaridade da mãe e da renda familiar, que aparecem associadas às práticas e crenças sobre cuidados infantis. Quando a escolaridade e a renda são altas, existiria uma maior probabilidade de os pais escolherem a creche como forma de cuidado alternativo. Para este grupo, a creche apareceria como um lugar seguro, em que existe uma proposta educativa e oportunidades para a criança interagir com outras crianças. Estes achados contrariam, em parte, o senso comum, no qual prevalece a idéia de que a creche é uma forma de cuidado para crianças pobres. Na verdade, quando não existe um subsídio governamental ou de empresas, colocar a criança numa creche de boa qualidade é mais caro do que deixar com parentes ou vizinhos.

Uma outra questão que se destaca na revisão acima é que mesmo entre as mães que não trabalham fora algumas têm escolhido um cuidado alternativo para o filho. Entre possíveis explicações, é provável que estas mães sintamse, por vezes, sobrecarregadas com as tarefas domésticas e as relacionadas à maternidade e podem ver no cuidado alternativo uma oportunidade para satisfazer sua necessidade de dedicar um tempo para si. Mas, também é plausível que isto ocorra especialmente entre aquelas que acreditam que a creche se constitui em um bom ambiente para socialização e educação do seu filho.

É importante salientar que não existe receita pronta em relação à escolha de uma forma de cuidado para o bebê ou criança pequena. As características da criança, o contexto familiar e social e as opções de cuidado alternativo devem ser analisados para identificar a melhor opção. Entretanto, deve-se sempre avaliar a qualidade do cuidado, do cuidador e do ambiente em que a criança deverá permanecer e estar atento às reações e mudanças comportamentais que ocorrem após o seu ingresso em determinada forma de cuidado alternativo. Diante de eventuais sinais de sofrimento, os pais devem reavaliar as condições de cuidado que a criança tem recebido e procurar identificar o que pode ser feito para evitar seu sofrimento. Além disso, independentemente da forma de cuidado escolhida, é aconselhável que os pais realizem uma adaptação gradativa do bebê e da criança pequena ao cuidado alternativo escolhido. Uma adaptação progressiva deve ser a regra, durante a qual os pais devem estar, inicialmente, presentes, e com o tempo de permanência aumentando gradualmente se ausentarem, de acordo com as condições do bebê/criança. Neste sentido, é importante que a mulher possa planejar a volta ao trabalho para que este processo de adaptação possa ser realizado de forma adequada, evitando que haja uma separação abrupta do bebê/criança de sua mãe. Por fim, uma escolha consciente e satisfatória contribuirá para evitar trocas freqüentes de cuidadores. Os bebês e crianças pequenas necessitam de estabilidade nos cuidados recebidos para poderem estabelecer boas relações afetivas e vínculos de confiança e, nesse contexto, trocas de cuidadores, a princípio, não contribuem para o seu desenvolvimento.
Enquanto para muitos pais o cuidado alternativo se constitui numa exigência por força da necessidade de trabalhar, para outros pode constituir uma opção relacionada a necessidades das mães de terem mais espaço pessoal, ou em função da crença sobre a importância social e educacional do cuidado alternativo, especialmente no caso da creche. Independentemente das razões que levam os pais a colocarem o bebê e a criança pequena na creche, este tende a ser um período difícil, se não para os pais, pelo menos para as crianças. Um cuidado alternativo adequado pode evitar o sofrimento da criança e eventuais conseqüências negativas para seu desenvolvimento. Nesse sentido, é muito importante que os pais e a sociedade em geral dêem muita atenção a este momento de transição na vida da criança. Em função da extensão do papel da creche como alternativa na sociedade atual, urge que as autoridades passem a avaliar cuidadosamente cada uma destas instituições, para que se tenham parâmetros mais claros sobre as condições mínimas que cada uma deve oferecer. Como está em jogo a formação emocional, social e educacional das novas gerações, não é possível que se deixe nas mãos de leigos a função de criar e manter uma creche. Nem, tampouco, se pode esperar que as forças de mercado criem um contexto de competição entre as creches, forçando-as a oferecerem um melhor atendimento, ou então que os pais, em sua grande maioria também leigos sobre atendimento infantil, possam, em uma visita à creche ou em um contato com a direção da creche, avaliar adequadamente a escolha que irão fazer.

Todas as creches deveriam ter um padrão adequado de funcionamento e não se constituírem em meros "depósitos de crianças". À semelhança do que se faz com o ensino superior, as autoridades deveriam fiscalizar e avaliar criteriosamente cada creche. Seria um enorme serviço prestado aos pais e à sociedade. Aos pais, por deixá-los mais tranqüilos de que seu(sua) filho(a) está sendo adequadamente atendido(a). À sociedade, por entender que a formação das novas gerações cada vez mais passa pelas creches e pré-escolas, e que estas precisam ter condições de oferecer, não só cuidados básicos como alimentação e higiene, mas também uma atenção diferenciada para cada faixa etária que facilite o desenvolvimento emocional, social e educacional do bebê e da criança pequena. Qualquer atendimento que não atinja isto, constituirá um desserviço à criança, aos pais e à sociedade.

\section{Referências}

Amorim, K. S. (1997). Processo de (re)construção de relações, papéis e concepções, a partir da inserção de bebês na creche. Dissertação de Mestrado nãopublicada, Faculdade de Filosofia, Ciências e Letras de Ribeirão Preto da Universidade de São Paulo, Ribeirão Preto.

Buffardi, L. C., \& Erdwins, C. J. (1994). Different types of day care and their relationship to maternal satisfaction, perceived support and role conflict. Child \& Youth Care Forum, 23(1), 41-54.

Carey, W. B., \& McDevitt, S. C. (1997). Coping with children's temperament. Nova York: BasicBooks.

Davies, N. S., \& Thornburg, K. R. (1994). Child care: a synthesis of research. Early Child Development and Care, 98, 39-45. 
Dunkel-Schetter, C., Sagrestano, L. M., Feldman, P., \& Killingsworth, C. (1996). Social support and pregnancy: a comprehensive review focusing on ethnicity and culture. In G. R. Pierce, B. Sarason, \& I. G. Sarason (Orgs.), Handbook of social support and the family (pp.375-412). Nova York: Plenum.

Erdwins, C. J., Casper, W. J., \& Buffardi, L. C. (1998). Child care satisfaction: the effects of parental gender and type of child care used. Child \& Youth Care Forum, 27(2), 111-123.

Fuller, B., Holloway, S., \& Liang, X. (1996). Family selection of child-care centers: the influence of household support, etnicity and parental practices. Child Development, 67, 3320-3337.

Galambos, N. L., \& Lerner, J. V. (1987). Child caracteristics and the employment of mother with young children: a longitudinal study. Journal of Child Psychology and Psychiatry, 28, 87-98.

Hertz, R., \& Ferguson, F. (1996). Childcare choice and constraints in the United States: social class, race and the influence of the family views. Journal of Comparative Family Studies, 27(2), 249-279.

INEP/MEC (2001). Estatísticas educacionais - censo infantil - a educação infantil no Brasil 1994-2001. Disponível em www.inep.gov. Obtido em 15 de junho de 2002.

Long, P., Wilson, P., Kutnick, P., \& Telford, L. (1996). Choice and childcare: a survey of parental perceptions and views. Early Child Developmental and Care, 119, 51-63.
Lordelo, E. A. (1997). Efeitos da experiência de creche no desenvolvimento da criança: uma revisão. Psicologia: Teoria e Pesquisa, 13(2), 221-229.

McKim, M., Stuart, B., \& O'Connor, D. L. (1996). Infant care: evaluation of pre-care differences hypotheses. Early Education and Development, 7(2), 107-119.

McMahon, L. (1994). Responding to defences against anxiety in day care for young children. Early Child Development and Care, 97, 175-184.

Rosemberg, F. (1995) A criação de filhos pequenos: tendências e ambigüidades contemporâneas In I. Ribeiro \& A. C. T. Ribeiro (Orgs.), Família em processos contemporâneos: inovações culturais na sociedade brasileira (pp. 167-190). São Paulo: Loyola.

Rossetti-Ferreira, M. C., Amorim, K. S., \& Vitória, T. (1994). A creche enquanto contexto possível de desenvolvimento da criança pequena. Revista Brasileira de Crescimento e Desenvolvimento Humano, IV, 35-40.

Scarr, S. (1998). American child care today. American Psychologist, 53, 95-108.

Singer, J. D., Fuller, B., Keiley, M., K., \& Wolf, A. (1998). Early child-care selection: variation by geographic location, maternal characteristics, and family structure. Developmental Psychology, 34(5), 1129-1144.

Sua criança do nascimento até os cinco. (1998). Veja Edição Especial, ano 31, n ${ }^{\mathrm{o}}$ 19 , p. 81.

Varin, D., Crugnola, C. R., Molina, P., \& Ripamonti, C. (1996). Sentisitive periods in the development of attachment and the age of entry into day care. European Journal of Psychology of Education, XI, 215-229.

1 Este artigo se constitui em requisito parcial do curso de doutorado em Psicologia do Desenvolvimento da Universidade Federal do Rio Grande do Sul e foi desenvolvido durante a disciplina de Psicologia do Desenvolvimento II.

Andrea Rapoport, mestre e doutoranda em Psicologia do Desenvolvimento na Universidade Federal do Rio Grande do Sul, é professora de Psicologia e Pedagogia nas Faculdades de Taquara. Endereço para correspondência: Instituto de Psicologia da Universidade Federal do Rio Grande do Sul; Rua Ramiro Barcelos, 2600/ 111; Porto Alegre, RS; CEP 90035.003. Tel.: (51) 3330-4623 ou 9806-6388. E-mail: deiar@ terra.com.br Cesar A. Piccinini, doutor em Psicologia por University College London (Reino Unido), é professor no curso de pós-graduação em Psicologia do Desenvolvimento da Universidade Federal do Rio Grande do Sul. 